\title{
ROUTING OF TRANSMITTER AND OTHER CHANGES IN FAST AXONAL TRANSPORT AFTER TRANSECTION OF ONE BRANCH OF THE BIFURCATE AXON OF AN IDENTIFIED NEURON ${ }^{1}$
}

\author{
JOHN M. ALETTA ${ }^{2}$ AND DANIEL J. GOLDBERG ${ }^{3}$ \\ Departments of Pharmacology and Neurology and Center for Neurobiology and Behavior, Columbia University College of \\ Physicians and Surgeons, New York, New York 10032
}

Received October 28, 1983; Revised January 24, 1984; Accepted January 30, 1984

\begin{abstract}
The regulation of the quantities and types of organelles that leave the neuronal cell body destined for use in the axon and its terminals is not well understood. We had previously found that transport of transmitter undergoes a precise down regulation when most of one branch of the bifurcate axon of an identified serotonergic neuron was removed. We have now investigated further the nature of the regulatory event and the reason for its initiation by eliminating portions of the axonal tree of this neuron. We find that the down regulation is more likely to be due to the loss of synapses than of axon because transport of $\left[{ }^{3} \mathrm{H}\right]$ serotonin decreases as much when an axonal branch is transected distally as after a proximal transection. Transport of $\left[{ }^{3} \mathrm{H}\right]$ fucosyl glycoprotein, which normally is associated with the serotonergic vesicle in this axon, decreases to the same extent as transport of $\left[{ }^{3} \mathrm{H}\right]$ serotonin following proximal transection. The glycoprotein down regulation occurs much more rapidly, possibly due to an inhibition of vesicle synthesis. A secondary rise in transport of $\left[{ }^{3} \mathrm{H}\right]$ fucosyl glycoprotein 3 days to 2 weeks after axotomy suggests that the radiolabeled glycoprotein has undergone a redistribution into organelles not normally labeled and transported in intact neurons in large amounts, since $\left[{ }^{3} \mathrm{H}\right]$ serotonin transport remains stably diminished during this period. We also describe here a case of routing of rapidly transported material. When one axonal branch is cut far from the point of bifurcation $(\sim 10 \mathrm{~mm}),\left[{ }^{3} \mathrm{H}\right]$ serotonin is directed away from the branch lacking its synaptic terminals and into the remaining intact branch even though the transected branch is physically capable of transporting its normal amount of $\left[{ }^{3} \mathrm{H}\right]$ serotonin. We suggest that the presence of synaptic endings influences both the export of transmitter vesicles from the cell body and the partitioning of vesicles among axon collaterals.
\end{abstract}

Fast axonal transport supplies axon collaterals and terminals with newly synthesized organelles and macromolecules from the cell body of the neuron (Ochs, 1982). The collaterals and terminals are themselves incapable of synthesizing these materials. In a healthy mature

\footnotetext{
${ }^{1}$ This work was supported by National Institutes of Health Research Grant NS 14711. Additional support was provided by National Institutes of Health Training Grant GM 07182 (J. M. A.), an Irma T. Hirschl Career Scientist Award (D. J. G.), and a Biomedical Research Support Grant (Columbia Univeristy). We would like to thank Kathrin Hilten for help with the illustrations and our friends and colleagues in the Center for Neurobiology and Behavior for useful discussions.

${ }^{2}$ Present address: Department of Pharmacology, New York University School of Medicine, 550 First Avenue, New York, NY 10016.

${ }^{3}$ To whom requests for reprints should be addressed, at the Department of Pharmacology, Columbia University College of Physicians and Surgeons, 630 West 168th Street, New York, NY 10032.
}

neuron, a major demand placed on the cell body by its peripheral field is for neurotransmitter storage vesicles used in synaptic transmission. Developing neurons and adult neurons whose axons are regenerating following transection presumably transport principally materials involved in axon growth. How a neuron regulates the numbers and types of organelles it transports is not known. For example, in the case of axotomy, what is the signal(s) that causes the cell body to redirect its output from materials associated with synaptic transmission to materials required for axon regeneration, and how is this adjustment accomplished (for review, see Grafstein and McQuarrie, 1978)?

We have begun to address these questions using an identified molluscan neuron that exhibits a rapid and precise decrease of fast axonal transport of neurotransmitter after elimination of a portion of its axonal tree (Aletta and Goldberg, 1982). The likeliest cause of this 
down regulation seemed to us, on the basis of our previous results, to be a loss of information normally supplied by the disconnected axon branch or its synapses. Experiments reported here point to the synapses as the likelier source of this information. They also suggest that the down regulation is achieved by a decrease in the rate of formation of serotonergic vesicles rather than a change in the processing of the vesicles for export from the cell body.

Experiments reported here also provide evidence that factors other than the transporting capacities of the branches of the axonal tree can determine how vesicles are partitioned among those branches. The question of how the destinations of organelles transported from the cell are determined is of considerable interest. For example, branches of an axon may give rise to synaptic fields of differing size which would likely require differing amounts of vesicles and other materials associated with synaptic transmission. Also, different branches may require different sets of macromolecules, especially during development when regional specializations are being established. Quantitative asymmetries of materials transported into the peripheral and central branches of mammalian peripheral sensory ganglia have been found (Lasek, 1968; Ochs, 1972; Komiya and Kurokawa, 1978; Brimijoin et al., 1980), but it is difficult to prove that these are not simply the result of asymmetries in transport capacity. Other data, in fact, have indicated a lack of selectivity in transport (Stone and Wilson, 1979; Bisby, 1981; Perry and Wilson, 1981).

Some of the results reported here have appeared in a preliminary report (Aletta and Goldberg, 1983).

\section{Materials and Methods}

Experimental preparation. We used a pair of giant, identified serotonergic neurons from the central nervous system of the marine mollusc, Aplysia californica. These cells, known as the giant cerebral neurons (GCNs), are invariably found on the dorsal rostral surface of the cerebral ganglion (Fig. 1). Each sends out a single axon which bifurcates while still in the ganglion at a distance of roughly $1 \mathrm{~mm}$ from the soma. One branch of the axon is in the ipsilateral cerebrobuccal connective (CBC) which connects the cerebral ganglion to the paired buccal ganglia about $10 \mathrm{~mm}$ distant. This branch ramifies within those buccal ganglia, with branches synapsing on cells in both ganglia and others running in buccal nerves to terminate on muscle cells in the underlying buccal mass (Weiss et al., 1978). The other axonal branch is in the ipsilateral posterior lip nerve (PLN), which connects the cerebral ganglion to the lip musculature 20 to $25 \mathrm{~mm}$ away. Thus, the synaptic fields of the two branches are spatially separate.

Transection of nerves. All transections were done in live, anesthetized animals through a small incision in the ventral surface of the head which was then sutured closed, and the animal was returned to a holding tank containing artificial sea water. In most experiments, the $\mathrm{CBC}$ on one side of the cerebral ganglion was transected either near the cerebral ganglion (proximal transection, Fig. 1, arrow $A$ ) or near the ipsilateral buccal ganglion

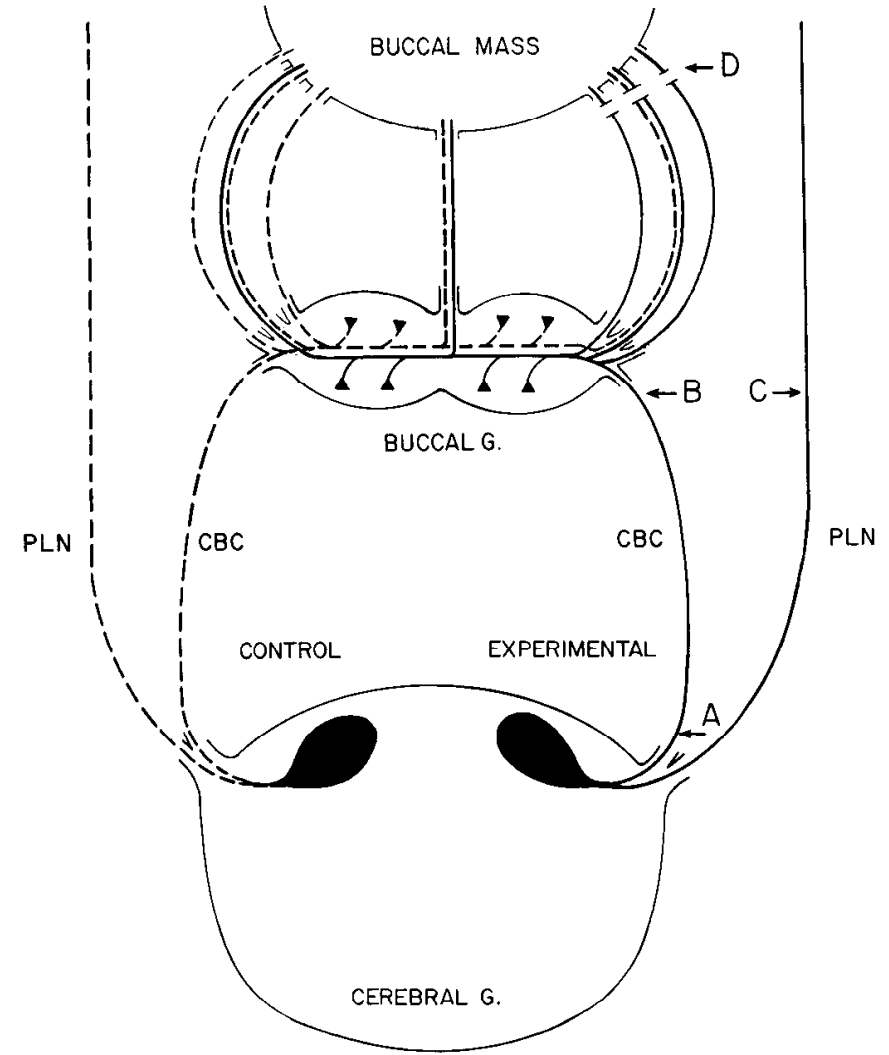

Figure 1. Schematic diagram of the symmetrical pair of GCNs in the cerebral ganglion. The solid and dotted lines leaving the cells respectively represent the experimental and control axonal distributions relevant to this study. Each CBC axon ramifies within the buccal ganglia, sending branches into all ipsilateral buccal nerves and at least one contralateral buccal nerve, all of which lead to the buccal mass. The PLN axons terminate in the lip musculature. Arrows mark sites of nerve transection performed in vivo in order to investigate the effects of a reduced peripheral field.

(distal transection, Fig. 1, arrow B). The GCN on the other side of the ganglion, whose axon was undisturbed, served as the control cell. In some experiments, the CBC was not cut, but the three buccal nerves connecting one buccal ganglion to the buccal mass were transected near the mass (Fig. 1, arrow D). The contralateral, as well as the ipsilateral, GCN has at least one axonal branch in these nerves (Weiss and Kupfermann, 1976) and so could not be used as a control cell. Rather, intact GCNs from animals received by the laboratory at the same time as the experimental animals were used as control cells. At various times after surgery, the cerebral ganglion with attached CBCs and PLNs was removed from the animal. It was then immediately pinned in an electrophysiological chamber whose floor was coated with a silicone plastic (Sylgard, Dow Corning) and which was filled with a solution of artificial sea water supplemented with amino acids, vitamins, and glucose.

Assay of axonal transport. Intrasomatic pressure injection of $\left[{ }^{3} \mathrm{H}\right]$ serotonin $(10$ to $20 \mathrm{Ci} / \mathrm{mmol}$, Amersham) or $\left[{ }^{3} \mathrm{H}\right]$ fucose $(56 \mathrm{Ci} / \mathrm{mmol}$, New England Nuclear; $67 \mathrm{Ci} /$ mmol, Amersham) into the GCNs was achieved using double-barreled glass microelectrodes (Goldberg et al., 
1976). Transport of $\left[{ }^{3} \mathrm{H}\right]$ serotonin into the two axonal branches was measured $3 \mathrm{hr}$ after injection, while transport of $\left[{ }^{3} \mathrm{H}\right]$ fucosyl glycoprotein was measured $6 \mathrm{hr}$ after injection (Aletta and Goldberg, 1982). Transport is expressed as the percentage of the total $\left[{ }^{3} \mathrm{H}\right]$ serotonin or $\left[{ }^{3} \mathrm{H}\right]$ fucosyl glycoprotein in the neuron (total = cell body $+\mathrm{CBC}+$ PLN) that appears in the axonal branch or branches. We do this to normalize the data, thereby avoiding the difficult task of injecting identical amounts of radioactivity into the experimental and control cells of a pair. The percentage of $\left[{ }^{3} \mathrm{H}\right]$ serotonin transported is independent of the size of the injection provided that between approximately 0.1 and $4.0 \mathrm{pmol}$ of $\left[{ }^{3} \mathrm{H}\right]$ serotonin are injected (Goldman et al., 1976). The percentage of $\left[{ }^{3} \mathrm{H}\right]$ fucosyl glycoprotein transported is likewise independent of injection size (Fig. 2). $\left[{ }^{3} \mathrm{H}\right]$ Serotonin injected into the cell body labels mainly a characteristic type of nontransportable large lysosome; only a small percentage of the radioactivity in the cell body is associated with the serotonergic vesicle (Schwartz et al., 1979). Similarly, only a fraction of injected $\left[{ }^{3} \mathrm{H}\right]$ fucose in the cell body is associated with the vesicle, with much of the radioactivity associated with other types of nontransportable organelles (L. J. Cleary and J. H. Schwartz, unpublished observations). Thus, changes in the percentage of neuronal radioactivity transported should reflect changes in the amounts of serotonin and fucosyl glycoprotein transported even if the number of serotonergic vesicles in the cell body changes. All experiments were carried out on cells having resting membrane potentials of at least -40
$\mathrm{mV}$ and antidromic action potentials greater than 50 $\mathrm{mV}$.

Assay of incorporation of fucose into glycoprotein. During our initial experiments on glycoprotein transport, we observed that the dependence of incorporation of $\left[{ }^{3} \mathrm{H}\right]$ fucose into glycoprotein on the amount of $\left[{ }^{3} \mathrm{H}\right]$ fucose injected into the cell was described by a hyperbolic function (Fig. 2). Thus, in order to compare accurately $\left[{ }^{3} \mathrm{H}\right]$ fucose incorporation into glycoprotein in control and experimental cells, equal volumes of the same stock solution of $\left[{ }^{3} \mathrm{H}\right]$ fucose were injected into each. Equality was obtained by measuring the length of the column of fluid in the microelectrode with a micrometer reticle mounted in the ocular of a stereo dissecting microscope. Six hours after the injections, the neurons were homogenized and $\left[{ }^{3} \mathrm{H}\right]$ fucosyl glycoprotein was determined as described previously (Aletta and Goldberg, 1982).

\section{Results}

Effect of transection of one branch of the bifurcate axon on transport of $\left[{ }^{3} \mathrm{H}\right]$ fucosyl glycoprotein. We previously reported that when the CBC branch of the bifurcate axon of GCN is transected next to the cerebral ganglion (Fig. 1 , arrow A), transport of $\left[{ }^{3} \mathrm{H}\right]$ serotonin decreases over 3 days to reach a new stable level, despite the fact that the PLN branch can and does transport, along with its normal complement of serotonergic vesicles, those that normally would have gone into the CBC (Aletta and Goldberg, 1982). As one step toward understanding the nature of the regulatory event in the cell body that gives

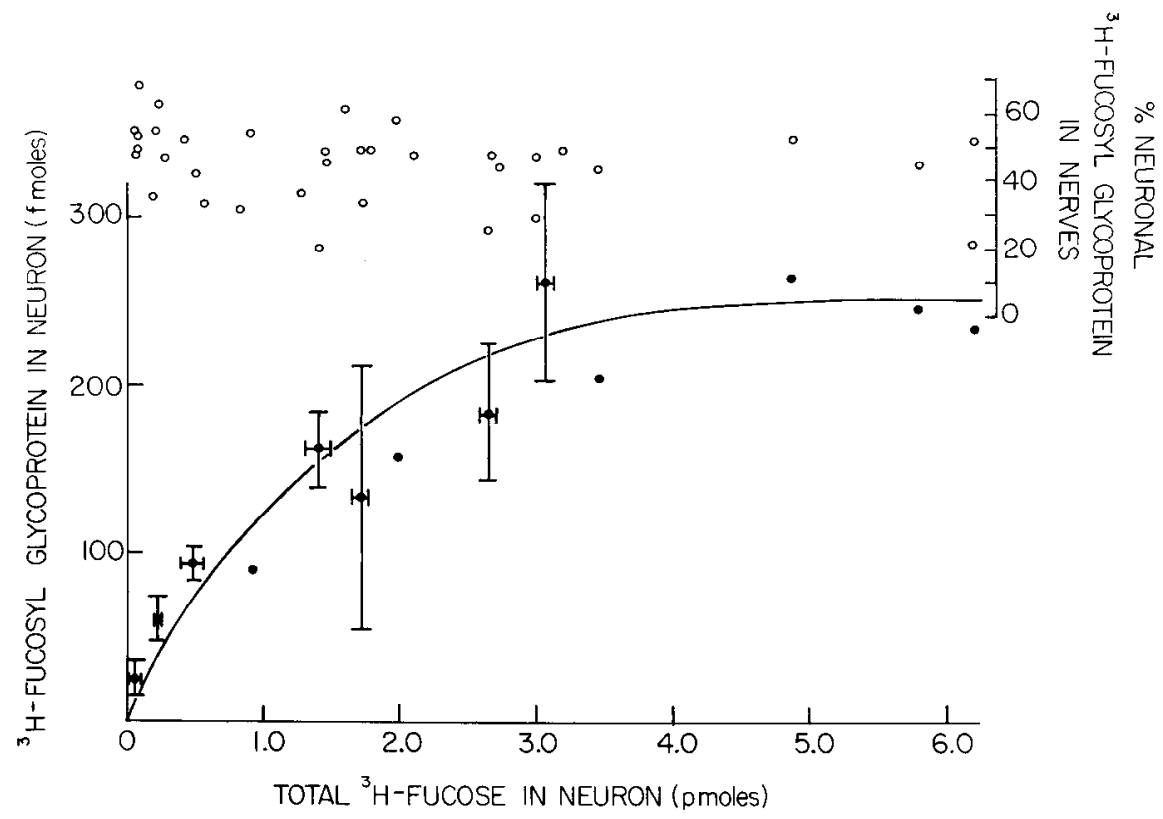

Figure 2. Incorporation and fast axonal transport of $\left[{ }^{3} \mathrm{H}\right]$ fucose in $\left[{ }^{3} \mathrm{H}\right]$ fucosyl glycoprotein of the GCN. Labeling $(\odot)$ and transport $(\mathrm{O})$ of fucosyl glycoproteins in 35 intact neurons over a 6 -hr period immediately after injection of [ $\left.{ }^{3} \mathrm{H}\right]$ fucose was measured as a function of the total amount of $\left[{ }^{3} \mathrm{H}\right]$ fucose present in the neuron $\left(\left[{ }^{3} \mathrm{H}\right]\right.$ fucose in the cell body plus [ $\left.\mathrm{H}\right]$ fucose in the axonal branches) at the end of each experiment. Individual determinations are presented for fast axonal transport. Results on the quantitative labeling of $\left[{ }^{3} \mathrm{H}\right]$ fucosyl glycoprotein were averaged over intervals of $0.3 \mathrm{pmol}$ of total intracellular $\left[{ }^{3} \mathrm{H}\right]$ fucose. Vertical and hortizontal bars through the data points indicate SEM of three or morc determinations. The curve was fitted to the points by eye. One picomole is equal to $33,500 \mathrm{cpm}$ or $48,160 \mathrm{cpm}$, depending upon the supplier of the radiolabeled fucose. 
rise to this decrease in transport, we wished to determine its time course more precisely, since our previouious results suggested that the event in the cell body might be substantially more rapid than the 3 days required for transport of $\left[{ }^{3} \mathrm{H}\right]$ serotonin to reach its new level (Aletta and Goldberg, 1982).

We studied the transport, following proximal transection of the CBC, of $\left[{ }^{3} \mathrm{H}\right]$ fucosyl glycoproteins. Like $\left[{ }^{3} \mathrm{H}\right]$ serotonin, they move by fast transport in the axon of GCN in the serotonergic vesicle (Cleary and Schwartz, 1982), but there is reason to believe that they label mainly vesicles synthesized after the injection of $\left[{ }^{3} \mathrm{H}\right]$ fucose into the cell, whereas $\left[{ }^{3} \mathrm{H}\right]$ serotonin seems to label members of the substantial pre-existing somal pool of vesicles as well as those synthesized after the injection (see "Discussion"). The reduction in transport of $\left[{ }^{3} \mathrm{H}\right]$ glycoprotein had not begun $3 \mathrm{hr}$ after transection but was significant by $12 \mathrm{hr}$ and complete within a day (Fig. 3; Table I). Thus, it progressed much more rapidly than the previously observed reduction in transport of $\left[{ }^{3} \mathrm{H}\right]$ serotonin.

Transport of $\left[{ }^{3} \mathrm{H}\right]$ fucosyl glycoprotein began to rise 3 days after transection, surpassing transport in the control neuron within 2 weeks of the injury (Fig. $3 A$ ). Of the $\left[{ }^{3} \mathrm{H}\right]$ fucosyl glycoprotein transported at 2 weeks, only $10 \%$ went into the $\mathrm{CBC}$, unsurprising since only a $1-\mathrm{mm}$ stump remained (Table $\mathrm{I}$ ). When the $\mathrm{CBC}$ was transected so as to leave a much longer length of nerve connected to the cerebral ganglion $(\sim 10 \mathrm{~mm}$; Fig. 1 , arrow $B)$, however, a large portion (41\%) of the transported $\left[{ }^{3} \mathrm{H}\right]$ fucosyl glycoprotein entered the CBC (Table I).

Effect of proximal transection on the incorporation of $\left[{ }^{3} H\right]$ fucose into glycoproteins. The more rapid rate of decline in the transport of $\left[{ }^{3} \mathrm{H}\right]$ fucosyl glycoprotein could be explained by an axotomy-induced decrease in the synthesis of serotonergic storage vesicles. To test this hyothesis, we measured total fucosylation of proteins in single neurons by injecting equal calibrated amounts of $\left[{ }^{3} \mathrm{H}\right]$ fucose ( 25 to $250 \mathrm{fmol}$ ) into both GCNs $24 \mathrm{hr}$ after proximal transection of the $\mathrm{CBC}$ on one side of the cerebral ganglia, a time at which maximal down regulation of $\left[{ }^{3} \mathrm{H}\right]$ fucosyl glycoprotein transport is manifest. If axotomy inhibits glycoprotein synthesis, post-transla-
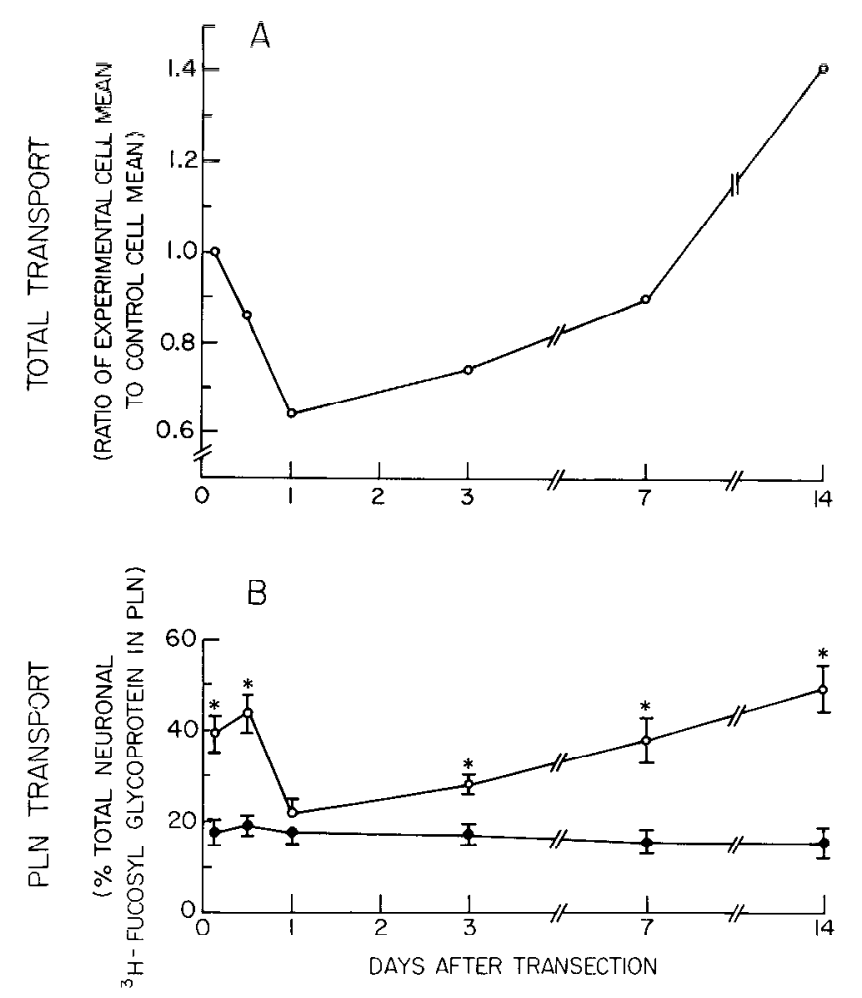

Figure 3. Time course of changes in fast axonal transport of $\left[{ }^{3} \mathrm{H}\right]$ fucosyl glycoprotein in the GCN after proximal transection of the CBC (Fig. 1, arrow $A$ ). A, Ratio of the mean total transport of $\left[{ }^{3} \mathrm{H}\right]$ fucosyl glycoprotein into the experimental PLN and CBC stump to the mean total transport in contralateral control cell nerves is plotted versus time after transection (data from Table I). B, Transport of $\left[{ }^{3} \mathrm{H}\right]$ fucosyl glycoprotein in control (O) and experimental (O) PLNs expressed as percentage of total $\left[{ }^{3} \mathrm{H}\right]$ fucosyl glycoprotein (total $=$ cell body + $\mathrm{CBC}+\mathrm{PLN}$ ) appearing in the PLN at various times after transection. Asterisks denote significant differences from control as determined by paired $t$ tests $(p<0.01)$.

tional fucosylation of new glycopeptides should also decline. In six such experiments, incorporation of $\left[{ }^{3} \mathrm{H}\right]$ fucose into protein was reduced an average of $21 \%$ by transection of the CBC. However, the difference between

\section{TABLE I}

Fast axonal transport of $\left[{ }^{3} \mathrm{H}\right]$ fucosyl glycoprotein in the bifurcate axon of the GCN following transection of the CBC

Transport of $\left[{ }^{3} \mathrm{H}\right]$ fucosyl glycoprotein was assayed as described under "Materials and Methods" at times from 3 hr to 2 weeks after in vivo $\mathrm{CBC}$ transection. The means are expressed as percentage of total neuronal $\left[{ }^{3} \mathrm{H}\right]$ fucosyl glycoprotein $( \pm \mathrm{SEM})$ found in each nerve carrying an axonal branch of the GCN (Fig. 1).

\begin{tabular}{|c|c|c|c|c|c|c|c|}
\hline \multirow{2}{*}{$\begin{array}{l}\text { Time after } \\
\text { Transection }\end{array}$} & \multicolumn{3}{|c|}{ Control } & \multicolumn{2}{|c|}{ Experimental } & \multicolumn{2}{|c|}{ Total transport } \\
\hline & No. ${ }^{a}$ & $\mathrm{CBC}$ & PLN & $\mathrm{CBC}$ & PLN & Control & Experimental \\
\hline \multicolumn{8}{|c|}{ Proximal transection } \\
\hline $3 \mathrm{hr}$ & 6 & $29.7 \pm 4.5$ & $17.7 \pm 2.8$ & $8.8 \pm 2.1^{b}$ & $39.0 \pm 3.9^{b}$ & $47.4 \pm 5.4$ & $47.8 \pm 5.1$ \\
\hline $12 \mathrm{hr}$ & 5 & $37.2 \pm 3.2$ & $18.9 \pm 2.1$ & $4.5 \pm 2.4^{b}$ & $43.5 \pm 4.2^{b}$ & $56.1 \pm 3.2$ & $48.0 \pm 5.1^{b}$ \\
\hline $24 \mathrm{hr}$ & 10 & $27.3 \pm 2.9$ & $17.3 \pm 1.7$ & $6.8 \pm 1.2^{b}$ & $21.7 \pm 2.9$ & $44.6 \pm 4.2$ & $28.4 \pm 3.4^{b}$ \\
\hline $72 \mathrm{hr}$ & 6 & $28.2 \pm 3.1$ & $17.1 \pm 2.2$ & $5.6 \pm 1.5^{b}$ & $27.9 \pm 1.9^{b}$ & $45.3 \pm 4.0$ & $33.5 \pm 3.0^{b}$ \\
\hline 1 week & 5 & $31.1 \pm 6.0$ & $15.4 \pm 2.3$ & $4.1 \pm 1.4^{b}$ & $37.9 \pm 5.2^{b}$ & $46.5 \pm 7.7$ & $42.0 \pm 4.8$ \\
\hline 2 weeks & 5 & $23.6 \pm 2.8$ & $15.4 \pm 2.7$ & $5.5 \pm 3.0^{b}$ & $49.7 \pm 5.4^{b}$ & $39.0 \pm 5.4$ & $55.2 \pm 6.6^{b}$ \\
\hline \multicolumn{8}{|l|}{ Distal transection } \\
\hline 2 weeks & 5 & $25.7 \pm 4.1$ & $15.8 \pm 2.2$ & $22.5 \pm 5.0$ & $32.4 \pm 4.7^{b}$ & $41.5 \pm 5.6$ & $55.0 \pm 3.3^{b}$ \\
\hline
\end{tabular}

\footnotetext{
${ }^{a}$ Number of experiments.
}

${ }^{b} p<0.05$, paired $t$ test. 
experimental and control cells was not statistically significant (Table II). To maximize the effect, we assayed the incorporation of $\left[{ }^{3} \mathrm{H}\right]$ fucose into protein $24 \mathrm{hr}$ after cutting both the CBC and the PLN proximally (Fig. 1, arrow $A$ ). If peripheral feedback determines the amount of vesicle export via an effect upon synthesis, its near total elimination should produce a near maximal reduction in fucosylation of vesicle-associated glycoproteins. The result from this second series of experiments was an average reduction of $54 \%$ in incorporation of $\left[{ }^{3} \mathrm{H}\right]$ fucose into protein (Table II).

Transport of $\left[{ }^{3} \mathrm{H}\right]$ serotonin following distal transections. The loss of information normally provided by the CBC axon or its associated synapses seems to us to be the most likely cause of the reduction in export of $\left[{ }^{3} \mathrm{H}\right]$ serotonin and $\left[{ }^{3} \mathrm{H}\right]$ fucosyl glycoprotein after transection (Aletta and Goldberg, 1982). This could be structurally encoded information in the axon such as the extent of the cytoskeleton or the volume of axoplasm. Alternatively, the information may originate from the CBC synapses and require the axon only as a conduit for retrograde transport to the cell body. We tried to distinguish between these possibilities by transecting the CBC farther from the cerebral ganglion (Fig. 1, arrow B). This procedure virtually eliminates $\mathrm{CBC}$ synapses but leaves in continuity with the cell body of GCN a 10 -fold longer length of that axonal branch than after proximal transection. After injecting $\left[{ }^{3} \mathrm{H}\right]$ serotonin into GCNs injured in this way, we followed the time course of changes in

TABLE II

Effect of proximal transection of either one or both axonal branches of the GCN bifurcate axon on incorporation of $\left[{ }^{3} H\right]$ fucose into glycoprotein

Equal volumes of a concentrated stock solution of $\left[{ }^{3} \mathrm{H}\right]$ fucose were microinjected into a pair of GCNs, one of which had suffered either partial or complete elimination of its axonal arbor (Fig. 1, at the site of arrow A) $24 \mathrm{hr}$ prior to injection. Six hours later each cell and the axon attached to it were assayed for $\left[{ }^{3} \mathrm{H}\right]$ fucosyl glycoprotein as described under "Materials and Methods." The means of the ratios (experimental/control) of individual results are presented \pm SEM.

\begin{tabular}{lcc}
$\begin{array}{c}\text { Branches } \\
\text { Transected }\end{array}$ & $\begin{array}{c}\text { No. of } \\
\text { Experiments }\end{array}$ & $\begin{array}{c}\text { Total Incorporation } \\
\text { (Experimental/Control } \\
+ \text { SFM) }\end{array}$ \\
\hline CBC & 6 & $0.79 \pm 0.14$ \\
CBC + PLN & 5 & $0.46 \pm 0.08^{a}$ \\
\hline
\end{tabular}

${ }^{a} p<0.01$, paired $t$ test. total neuronal export and PLN transport of $\left[{ }^{3} \mathrm{H}\right]$ serotonin.

Comparison with previous results from proximal transections indicates that the final level of down regulation achieved is essentially independent of the length of the axon stump (Fig. 4; Table III). Despite the extra length of axon attached to the cell body, diversion of $\left[{ }^{3} \mathrm{H}\right]$ serotonin into the PIN was apparent even $6 \mathrm{hr}$ after distal transection of the CBC (Table III; see below). Over

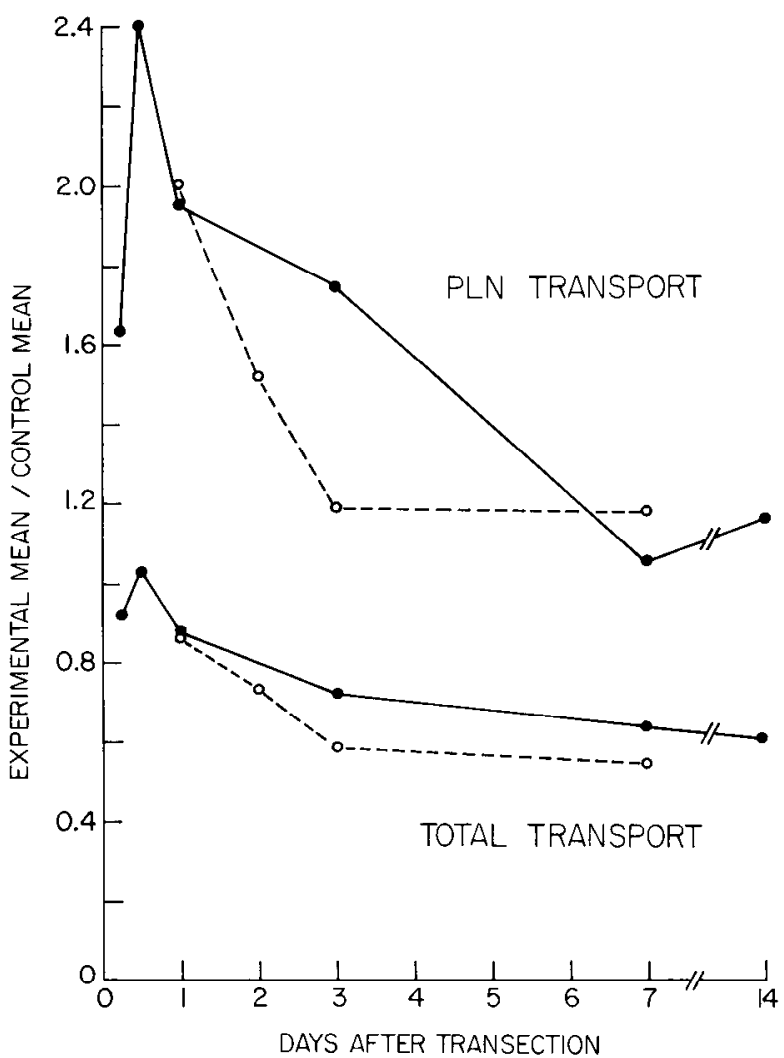

Figure 4. Comparison of the effects of proximal $\left(\mathrm{O}_{-}-\mathrm{O}\right)$ and distal (-) transection of the CBC on fast axonal transport of $\left[{ }^{3} \mathrm{H}\right]$ serotonin in the GCN. The ratio of experimental to control cell means for PLN (upper pair of curves) and total $\left[{ }^{3} \mathrm{H}\right]$ serotonin transport $(\mathrm{CBC}+\mathrm{PLN}$; lower pair of curves) are presented as a function of the time after transection. Data used to draw the distal transection curves appear in Table III, and the proximal transection curves are from our previous publication (Aletta and Goldberg, 1982).

TABLE III

Fast axonal transport of $\left[{ }^{3} \mathrm{H}\right]$ serotonin in the bifurcate axon of the GCN following distal transection of the $C B C$

Transport of $\left[{ }^{3} \mathrm{H}\right]$ scrotonin was assayed as described under "Materials and Methods" at times from $6 \mathrm{hr}$ to 2 weeks after in vivo $\mathrm{CBC}$ transection just before the GCN axon enters the buccal ganglion. The means are expressed as percentage of total neuronal [ $\left.{ }^{3} \mathrm{H}\right]$ serotonin $( \pm$ SEM) found in each nerve carrying an axonal branch of the GCN (Fig. 1).

\begin{tabular}{|c|c|c|c|c|c|c|c|}
\hline \multirow{2}{*}{$\begin{array}{l}\text { Time after } \\
\text { Transection }\end{array}$} & \multicolumn{3}{|c|}{ Control } & \multicolumn{2}{|c|}{ Experimental } & \multicolumn{2}{|c|}{ Total Transport } \\
\hline & No. ${ }^{a}$ & $\mathrm{CBC}$ & PLN & $\mathrm{CBC}$ & PLN & Control & Experimental \\
\hline $6 \mathrm{hr}$ & 4 & $14.9 \pm 9.1$ & $5.7 \pm 2.1$ & $9.6 \pm 3.2$ & $9.3 \pm 5.8$ & $20.6 \pm 11.1$ & $18.9 \pm 9.0$ \\
\hline $12 \mathrm{hr}$ & 4 & $8.6 \pm 0.7$ & $3.5 \pm 0.9$ & $4.1 \pm 0.6^{b}$ & $8.4 \pm 1.6^{b}$ & $12.1 \pm 1.3$ & $12.5 \pm 1.8$ \\
\hline $24 \mathrm{hr}$ & 7 & $14.7 \pm 1.9$ & $7.5 \pm 1.1$ & $4.8 \pm 0.9^{b}$ & $14.6 \pm 4.2^{b}$ & $22.2 \pm 2.6$ & $19.4 \pm 2.2$ \\
\hline $72 \mathrm{hr}$ & 7 & $19.9 \pm 2.1$ & $8.1 \pm 1.2$ & $5.9 \pm 1.0^{b}$ & $14.2 \pm 2.0^{b}$ & $28.0 \pm 3.1$ & $20.1 \pm 2.8^{b}$ \\
\hline 1 week & 7 & $15.4 \pm 1.5$ & $9.0 \pm 2.1$ & $6.0 \pm 0.6^{b}$ & $9.5 \pm 0.9$ & $24.4 \pm 1.4$ & $15.5 \pm 1.3^{b}$ \\
\hline 2 weeks & 4 & $12.0 \pm 1.4$ & $7.0 \pm 0.6$ & $3.4 \pm 0.8^{b}$ & $8.1 \pm 0.8$ & $19.0 \pm 1.6$ & $11.5 \pm 1.2^{b}$ \\
\hline
\end{tabular}

\footnotetext{
${ }^{a}$ Number of experiments
}

${ }^{b} p<0.01$, paired $t$ test. 
the course of 1 week, export of $\left[{ }^{3} \mathrm{H}\right]$ seerotonniñ declinied just enough to restore transport in the PLN to normal, as we had previously found with proximal transection. The down regulation took longer to achieve but was as complete with distal as with proximal transection. Down regulation of $\left[{ }^{3} \mathrm{H}\right]$ serotonin in this distally transected preparation was maintained for at least 1 additional week.

However, when the axonal branch was transected distally, but at a site that would disconnect from the cell body only some of the synapses of that branch, the reduction in transport of $\left[{ }^{3} \mathrm{H}\right]$ serotonin was much less pronounced. Transection of the three buccal nerves on one side (Fig. 1, arrow D) enabled us to maintain CBC synapses in the buccal ganglia while detaching those present in the buccal mass. Assay of the transport of $\left[{ }^{3} \mathrm{H}\right]$ serotonin 1 week after surgery showed that there

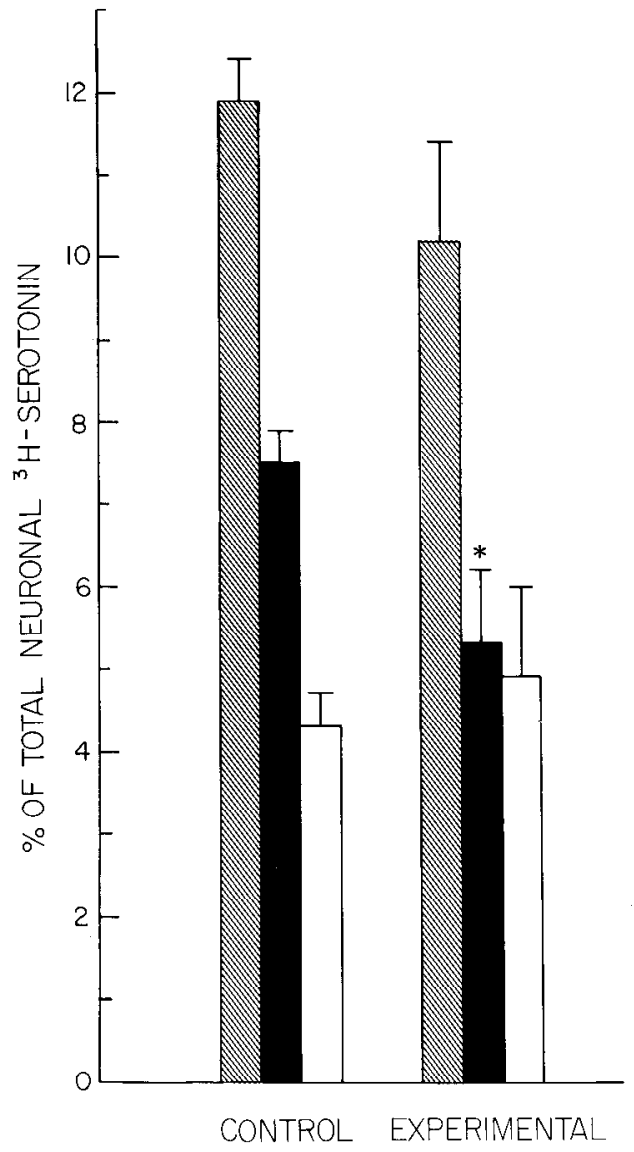

Figure 5. Effect of ipsilateral buccal nerve axotomies on fast axonal transport of $\left[{ }^{3} \mathrm{H}\right]$ serotonin in GCN. Total fast axonal transport of $\left[{ }^{2} \mathrm{H}\right]$ serotonin $(\mathrm{CBC}+\mathrm{PLN} /$ cell body $+\mathrm{CBC}+$ PLN) is illustrated with hatched bars, CBC transport with solid bars, and PLN transport with open bars. All three buccal nerves on one side of the buccal mass were usually cut at their point of entry into the muscle (Fig. 1, arrow $D$ ). In two experiments, the nerves were cut just as they left the ipsilateral buccal ganglion. The means \pm SEM from a total of eight experimental cells are presented along with the control cell means \pm SEM of 12 intact GCNs from animals received at the same time as the experimental animals. The asterisk denotes a statistically significant difference from control as determined by the Student's $t$ test $(p<0.02)$.

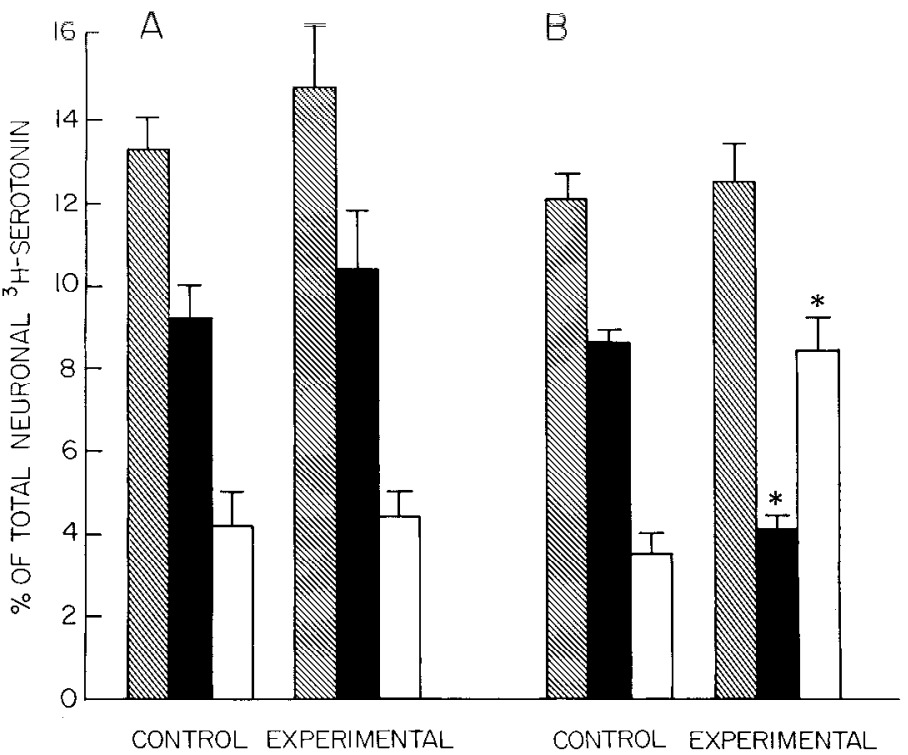

Figure 6. Routing of $\left[{ }^{3} \mathrm{H}\right]$ serotonin transport in GCN. Total fast axonal transport of $\left[{ }^{3} \mathrm{H}\right]$ serotonin $(\mathrm{CBC}+\mathrm{PLN} /$ cell body $+\mathrm{CBC}+\mathrm{PLN}$ ) is illustrated with hatched bars, $\mathrm{CBC}$ transport with solid bars, and PLN transport with open bars. A, Both the $\mathrm{CBC}$ and PLN of experimental GCNs were transected in vivo approximately $10 \mathrm{~mm}$ away from the cerebral ganglion (Fig. 1, arrows $B$ and $C) 12 \mathrm{hr}$ prior to the assay of $\left[{ }^{3} \mathrm{H}\right]$ serotonin transport. The contralateral GCNs served as control cells. $B$, Only the CBC of the experimental GCN was transected distally (Fig. 1, arrow B). The PLN was left undisturbed. Contralateral GCNs served as control cells. All results are the mean \pm SEM of four experiments. Asterisks denote significant differences from control as determined by paired $t$ tests $(p<0.01)$.

was a smaller reduction in CBC transport (Fig. 5) and, consequently, a smaller reduction in the ratio of the amounts transported in the CBC and PLN. This ratio was 1.74 in normal GCNs, 1.06 in GCNs whose axonal branches in the buccal nerves were transected, and 0.63 in GCNs whose axonal branch in the CBC was transected distally (Fig. 1, arrow B).

Routing of neurotransmitter. One day after the $\mathrm{CBC}$ is transected distally (Fig. 1, arrow B), transport of $\left[{ }^{3} \mathrm{H}\right]$ serotonin is not significantly decreased. We expected that such a transection would not impair the ability of the CBC to transport material, since it has been demonstrated frequently that normal, and even increased, amounts of material are transported in transected nerves (Grafstein and McQuarrie, 1978). We confirmed that distal transection of the $\mathrm{CBC}$ did not compromise its ability to transport $\left[{ }^{3} \mathrm{H}\right]$ serotonin injected into the cell body of GCN by measuring transport $12 \mathrm{hr}$ after both the CBC and PLN were transected distally (Fig. 1, arrows $B$ and $C$ ). Transport was normal (Fig. $6 A$ ).

This result allowed us to determine whether the GCN would transport $\left[{ }^{3} \mathrm{H}\right]$ serotonin into a branch capable of carrying it but lacking synaptic terminals, when presented with the alternative route of a branch ending in synaptic terminals. We measured the transport of $\left[{ }^{3} \mathrm{H}\right]$ serotonin $12 \mathrm{hr}$ after the CBC had been transected distally (Fig. 1, arrow $B$ ) but the PLN had been left untouched. $\left[{ }^{3} \mathrm{H}\right]$ Serotonin was diverted from the $\mathrm{CBC}$ into 
the PLN (Fig. 6B). The transected CBC transported less than $50 \%$ of the contralateral control CBC, and the experimental PLN proportionately more than its control. Thus, transmitter is directed away from an axonal branch lacking its synaptic endings and into an intact branch even when the lesioned branch is physically able to transport normal quantities of transmitter.

\section{Discussion}

Nature of the regulatory event responsible for down regulation of fast transport. We had previously shown that elimination of one branch of a bifurcate axon results in a rapid and precise reduction in the amount of neurotransmitter undergoing fast axonal transport, despite the fact that the remaining branch can and does transport the transmitter that would normally move in the disconnected branch. Evidence presented here gives us additional insight into the cause of this down regulation and the mechanism whereby the cell body effects it.

There are two likely alternative explanations to account for the decreased export of $\left[{ }^{3} \mathrm{H}\right]$ serotonin and $\left[{ }^{3} \mathrm{H}\right]$ fucosyl glycoprotein following axotomy. Either fewer storage vesicles are synthesized, or once synthesized their processing in the cell body is altered so that fewer are exported into the axon. This latter situation might result, for example, from a decrease in the efficiency of loading of the organelles onto the transport machinery in the axon or from an increased rate of degradation of vesicles normally destined for export. A decrease in the rate of synthesis of vesicles seems to us the likelier cause based on our previous findings and the results presented in this report.

Decreased vesicle synthesis is suggested by our observation that the progression of down regulation of $\left[{ }^{3} \mathrm{H}\right]$ fucosyl glycoprotein is more rapid than that of $\left[{ }^{3} \mathrm{H}\right]$ serotonin (Fig. 3A; Aletta and Goldberg, 1982). At early times after injection of $\left[{ }^{3} \mathrm{H}\right]$ fucose into $\mathrm{GCN}$, it is associated predominately with serotonergic storage vesicles (Cleary and Schwartz, 1982). It is probably mostly in vesicles synthesized after the injection. This is implied by the findings that when protein synthesis in Aplysia neurons is blocked, transport of $\left[{ }^{3} \mathrm{H}\right]$ fucosyl glycoprotein virtually stops within $2 \mathrm{hr}$ (Ambron et al., 1975), whereas transport of $\left[{ }^{3} \mathrm{H}\right]$ serotonin continues in gradually diminishing amounts for much longer (Goldberg et al., 1978). Probably, then, $\left[{ }^{3} \mathrm{H}\right]$ fucose is mostly incorporated into newly synthesized vesicles, while $\left[{ }^{3} \mathrm{H}\right]$ serotonin labels a substantial pre-existing somal pool of vesicles as well as those newly formed. Such a difference would be expected from the facts that amine transmitters in the cytoplasm are thought to be readily exchangeable with transmitter in the vesicle interior (Fillenz, 1977), whereas $\left[{ }^{3} \mathrm{H}\right]$ fucose is incorporated into glycoproteins that are components of the vesicle membrane (Ambron et al., 1974, 1980). Therefore our present results probably indicate that the transport of newly synthesized vesicles decreases more rapidly than the overall transport of vesicles. This is consistent with a decrease in the rate of synthesis of vesicles being the cause of the decrease in the transport of vesicles following axon transection.

A second line of evidence which is in agreement with an axotomy-induced effect on vesicle production comes from our experiments on $\left[{ }^{3} \mathrm{H}\right]$ fucose incorporation into glycoprotein. Transportable $\left[{ }^{3} \mathrm{H}\right]$ glycoprotein comprises approximately 40 to $50 \%$ of the total somatic store of $\left[{ }^{3} \mathrm{H}\right]$ glycoproteins (Ambron et al., 1974; R. Ambron, personal communication). We find that there is a reduction in transport of approximately $40 \% 1$ day after proximal transection of the CBC (Fig. $3 A$ ). The $21 \%$ decrease in the incorporation of $\left[{ }^{3} \mathrm{H}\right]$ fucose into protein that accompanies this (Table II) is, thus, close to the 16 to $20 \%$ reduction expected if the decrease in transport resulted from a decrease in synthesis of vesicles. Transection of both branches of the bifurcate axon should presumably cause a maximal decrease in synthesis of transportable glycoprotein, and we found this to be true (Table II).

Although these results seem to favor the idea that axon transection causes a decrease in the rate of synthesis of vesicles, they are far from conclusive. For example, the extent of fucosylation of vesicular glycoproteins, rather than the rate of formation of the vesicles, may have decreased. Quantitative assessment by electron microscopic radioautography of the incorporation of $\left[{ }^{3} \mathrm{H}\right]$ leucine into vesicles in the cell body will be required for a definitive answer.

Increase of transport of $\left[{ }^{3} \mathrm{H}\right]$ fucosyl glycoprotein. Fast transport of $\left[{ }^{3} \mathrm{H}\right]$ fucosyl glycoprotein is not stably diminished following transection of one branch of the GCN. Within 3 days of transection, it has begun to rise, and it steadily increases over time until by 2 weeks later the injured neuron is transporting $42 \%$ more $\left[{ }^{3} \mathrm{H}\right]$ fucosyl glycoprotein than the contralateral control cell (Fig. 3A). A similar result for glycoproteins labeled with $\left[{ }^{3} \mathrm{H}\right]$ fucose has been found in crushed rabbit hypoglossal nerve (Frizell and Sjostrand, 1974). 'Total amounts of rapidly transported protein labeled with $\left[{ }^{3} \mathrm{H}\right]$ leucine have also been observed to increase in regenerating mammalian peripheral nerve (Griffin et al., 1976). Since transport of $\left[{ }^{3} \mathrm{H}\right]$ serotonin remains stably reduced during this period of time, this result may indicate that some of the $\left[{ }^{3} \mathrm{H}\right]$ fucosyl glycoprotein has been incorporated into organelles other than the transmitter vesicle as a consequence of axotomy. Perhaps these organelles are associated with axon injury or growth and as such are not prominent in mature intact neurons.

Source of peripheral feedback. Our previous results led us to propose that loss of information normally provided by the disconnected CBC axon or its synaptic terminals is the most likely cause of the down regulation of fast axonal transport of $\left[{ }^{3} \mathrm{H}\right]$ serotonin (Aletta and Goldberg, 1982). We now have reason to believe that the terminals are the more likely source of this information, because the extent of reduction of the transport of both $\left[{ }^{3} \mathrm{H}\right]$ serotonin and $\left[{ }^{3} \mathrm{H}\right]$ fucosyl glycoprotein is not substantially influenced by the length of the axonal branch left in continuity with the cell body, as long as all of the synapses are detached. In all cases, export declines just enough to return transport in the PLN approximately to normal (Figs. $3 B$ and 4). Watson (1970) has also emphasized the role of axon terminals in regulating the metabolic activity of the nerve cell body, and observations describing retrograde neurotrophic effects suggest that synapses play an active part in providing NGF (Thoenen 
and Barde, 1980) and other possible regulatory factors (Hendry and Hill, 1980) to the axon for transfer back to the cell body.

The increased time for full expression of the down regulation after distal transection (Fig. 4) might be due to the larger amounts of material of synaptic origin moving by retrograde transport in the longer axonal stump. If depletion of some component of this material elicits down regulation, then the longer time taken to exhaust this component would delay down regulation. This has been suggested (Cragg, 1970) as an explanation for the delay in the onset of nucleolar changes in rat hypoglossal neurons when their axons are injured far from, rather than close to, the cell bodies (Watson, 1968).

Routing of neurotransmitter. We have demonstrated here one situation in which the destination of material moving by fast axonal transport is determined by factors other than the transporting capacities of the branches of the axonal tree, that is, one situation in which routing of transported material occurs. Transport of transmitter away from an axonal branch lacking synaptic terminals occurs despite the fact that the branch is still capable of transporting normal amounts of transmitter (Fig. 6). Further evidence for routing of transmitter may come from our experiments on the partitioning of $\left[{ }^{3} \mathrm{H}\right]$ fucosyl glycoprotein between the $\mathrm{CBC}$ and PLN axons 2 weeks after distal transection of the CBC. The ratio of transport of $\left[{ }^{3} \mathrm{H}\right]$ serotonin in the CBC to that in the PLN at this time is 0.4 (Table III), while the ratio for total $\left[{ }^{3} \mathrm{H}\right]$ fucosyl glycoprotein is 0.7 (Table I); and we estimate the ratio for that portion of the total $\left[{ }^{3} \mathrm{H}\right]$ fucosyl glycoprotein whose transport increases following transection to be 1.1. ${ }^{4}$ (In normal cells, the ratios are insignificantly different: 1.8 for $\left[{ }^{3} \mathrm{H}\right]$ serotonin and 1.7 for $\left[{ }^{3} \mathrm{H}\right]$ fucosyl glycoprotein.) These data suggest that transported materials not associated with serotonin (as vesicular fucosyl glycoprotein is) are not diverted from the transected $\mathrm{CBC}$, although until we identify the individual fucosyl

\footnotetext{
${ }^{4}$ The $\left[{ }^{3} \mathrm{H}\right]$ fucosyl glycoprotein transported at long times after transection of the CBC consists of that portion of the $\left[{ }^{3} \mathrm{H}\right]$ fucosyl glycoprotein transported in a normal cell (associated predominantly with serotonergic vesicles) that continues to be transported after down regulation is complete (represented by the 1-day data point in Fig. $3 A$ ) and the incremental $\left[{ }^{3} \mathrm{H}\right]$ fucosyl glycoprotein resulting from axon injury (represented by the increase from the 1-day data point to the 2-week data point in Fig. $3 A$ ). The "old" glycoprotein should partition between the CBC and PLN as $\left[{ }^{3} \mathrm{H}\right]$ serotonin does, as in a normal cell. We can then estimate how the "new" partitions. Two weeks after distal transection of the CBC, transport of $\left[{ }^{3} \mathrm{H}\right]$ serotonin in the PLN of the experimental cell is $16 \%$ greater than in the PLN of the control cell (Table III). Thus, we can estimate "old" $\left[{ }^{3} \mathrm{H}\right]$ fucosyl glycoprotein in the PLN 2 weeks after distal transection to be $16 \%$ greater than in the PLN of the control cell, or $18.3 \%$ of total neuronal $\left[{ }^{3} \mathrm{H}\right]$ fucosyl glycoprotein $\left(1.16 \times 15.8 \%\right.$ (from Table I)). Subtracting this from the total $\left[{ }^{3} \mathrm{H}\right]$ fucosyl glycoprotein in the PLN of the experimental cell gives a value of $14.1 \%$ to "new" [ $\mathrm{H}$ ] fucosyl glycoprotein in the PLN. Performing similar calculations for the CBC $(0.28 \times 25.7 \%$ (from Table $\mathrm{I})=7.2 \%$; $22.5 \%$ (from Table I) $-7.2 \%=15.3 \%$ ), we estimate "new" $\left[{ }^{3} \mathrm{H}\right]$ fucosyl glycoprotein in the $\mathrm{CBC}$ to be $15.3 \%$ of total neuronal $\left[{ }^{3} \mathrm{H}\right]$ fucosyl glycoprotein. Thus, it appears that the "new," as yet uncharacterized, $\left[{ }^{3} \mathrm{H}\right]$ fucosyl glycoprotein partitions approximately equally $(\mathrm{CBC}=$ $15.3 \% ;$ PLN $=14.1 \%$ ) between the two axonal branches.
}

glycoproteins whose transport increases and directly measure their partitioning, a definitive conclusion in this regard cannot be drawn.

The results reported here, considered together with those reported earlier, suggest how transmitter vesicles are normally partitioned among the branches of the axon. It may be that the partitioning is determined by the relative number of synaptic terminals, or relative amounts of some related factor such as the volume of synaptoplasm in each axonal branch, with more vesicles going into branches with more terminals. We had found that when part of the axonal tree of GCN was removed, the reduction in transport of transmitter was proportional to the loss (Aletta and Goldberg, 1982), and the present results suggest that the important loss may be of terminals rather than axon. In addition, the present results show that when the transport has been reduced, the remaining transmitter undergoing transport does not partition among the axonal branches according to the transporting capacities of those branches. Rather, transmitter tends to be transported in branches that have synaptic terminals (Fig. 6). If this hypothesis is correct, then the loss of some, but not all, of the terminals from a branch should eventually reduce the percentage of total transported transmitter that it carries. We find this to occur when some of the synapses are detached from the CBC branch of the axon of GCN (Fig. 5). 'The ratio of transport of $\left[{ }^{3} \mathrm{H}\right]$ serotonin in this branch to transport in the PLN branch declines from 1.7 to 1.1 .

Although vesicles are partitioned according to some principle other than axonal transport capacity, we do not yet know whether other organelles are routed in GCN. For example, we cannot comment on the appropriateness of the partitioning of the extra $\left[{ }^{3} \mathrm{H}\right]$ fucosyl glycoprotein that is transported as a result of nerve injury, other than to note that it seems to partition differently from $\left[{ }^{3} \mathrm{H}\right]$ serotonin (see above). This is because, not yet knowing whether the transected CBC axon branch undergoes regrowth during the period we have studied, we do not know whether this glycoprotein is associated with regrowth or is just a byproduct of axon injury. Studies of mammalian dorsal root ganglion after transection of the peripheral nerve have suggested that proteins whose transport is increased following nerve injury are not routed specifically into the regenerating nerve (Bisby, 1981; Perry and Wilson, 1981).

Whatever the underlying basis for the quantitative aspect of partitioning, it is clear that the destinations of serotonergic vesicles in GCN are not determined until some time after their formation. A mechanism of routing that has been suggested is that the organelles destined for each branch of the axonal tree are synthesized at separate sites in the cell body, so that the site of synthesis determines the destination of the organelles (Ochs et al., 1978). This evidently cannot be true in our experiments, since the routing of $\left[{ }^{3} \mathrm{H}\right]$ serotonin indicates that old, as well as new, vesicles are routed.

In conclusion, these studies lead us to believe that there is a 2 -fold means for assuring that an appropriate number of transmitter vesicles arrive at a suitable destination. Routing causes vesicles to avoid axonal branches that lack synaptic terminals. Secondly, the 
process of down regulation causes the cell body to reduce its output just enough to adjust for decreased need.

\section{References}

Aletta, J. M., and D. J. Goldberg (1982) Rapid and precise down regulation of fast axonal transport of transmitter in an identified neuron. Science 218: 913-916.

Aletta, J. M., and D. J. Goldberg (1983) Routing of transmitter and modulation of fast axonal transport following transection of one branch of the bifurcate axon of an identified Aplysia neuron. Soc. Neurosci. Abstr. 9: 1192.

Ambron, R. T., J. E. Goldman, and J. H. Schwartz (1974) Axonal transport of newly synthesized glycoproteins in a single identified neuron of Aplysia californica. J. Cell Biol. 61: $665-675$.

Ambron, R. T., J. E. Goldman, and J. H. Schwartz (1975) Effect of inhibiting protein synthesis on axonal transport of membrane glycoproteins in an identified neuron of Aplysia. Brain Res. 94: 307-323.

Ambron, R. T., J. E. Goldman, L. J. Shkolnik, and J. H. Schwartz (1980) Synthesis and axonal transport of membrane glycoproteins in an identified serotonergic neuron of Aplysia. J. Neurophysiol. 43: 929-944.

Bisby, M. A. (1981) Axonal transport in the central axon of sensory neuror, during regeneration of their peripheral axon. Neurosci. Lett. 21: 7-11.

Brimijoin, S., J. M. Lundberg, E. Brodin, T. Hokfelt, and G. Nilsson (1980) Axonal transport of substance $P$ in the vagus and sciatic nerves of the guinea pig. Brain Res. 191: 443-457.

Cleary, L. J., and J. H. Schwartz (1982) Identification of the principle organelle carried by fast axonal transport in the giant cerebral neuron of Aplysia. Soc. Neurosci. Abstr. 8: 828.

Cragg, B. G. (1970) What is the signal for chromatolysis? Brain Res. 23: 1-21.

Fillenz, M. (1977) The factors which provide short-term and long-term control of transmitter release. Prog. Neurobiol. 8: $251-278$.

Frizell, M., and J. Sjostrand (1974) The axonal transport of $\left[{ }^{3} \mathrm{H}\right]$ fucose labelled glycoproteins in normal and regenerating peripheral nerves. Brain Res. 78: 109-123.

Goldberg, D. J., J. E. Goldman, and J. H. Schwartz (1976) Alterations in amounts and rates of serotonin transported in an axon of the giant cerebral neurone of Aplysia californica. J. Physiol. (Lond.) 259: 473-490.

Goldberg, D. J., J. H. Schwartz, and A. A. Sherbany (1978) Kinetic properties of normal and perturbed axonal transport of serotonin in a single identified axon. J. Physiol. (Lond.) 281: 559-579.

Goldman, J. E., K. S. Kim, and J. H. Schwartz (1976) Axonal transport of $\left[{ }^{3} \mathrm{H}\right]$ serotonin in an identified neuron of Aplysia californica. J. Cell Biol. 70: 304-318.

Grafstein, B., and I. G. McQuarrie (1978) Role of the nerve cell body in axonal regeneration. In Neuronal Plasticity, C. W. Cotman, ed., pp. 155-195, Raven Press, New York.

Griffin, J. W., D. B. Drachman, and D. L. Price (1976) Fast axonal transport in motor nerve regeneration. J. Neurobiol. 7: $355-370$.

Hendry, I. A., and C. E. Hill (1980) Retrograde axonal transport of target tissue-derived macromolecules. Nature 287: 647649.

Komiya, Y., and M. Kurokawa (1978) Asymmetry of protein transport in two branches of bifurcating axons. Brain Res. 139: 354-358.

Lasek, R. J. (1968) Axoplasmic transport in cat dorsal root ganglion cells: As studied with ${ }^{3} \mathrm{H}$-L-leucine. Brain Res. 7: 360-377.

Ochs, S. (1972) Rate of fast axoplasmic transport in mammalian nerve fibres. J. Physiol. (Lond.) 227: 627-645.

Ochs, S. (1982) Axoplasmic Transport and Its Relation to Other Nerve Functions, John Wiley \& Sons, New York.

Ochs, S., J. Erdman, R. A. Jersild, Jr., and V. McAdoo (1978) Routing of transported materials in the dorsal root and nerve fiber branches of the dorsal root ganglion. J. Neurobiol. 9: 465-481.

Perry, G. W., and D. L. Wilson (1981) Protein synthesis and axonal transport during nerve regeneration. J. Neurochem. 37: $1203-1217$.

Schwartz, J. H., L. J. Shkolnik, and D. J. Goldberg (1979) Specific association of neurotransmitter with somatic lysosomes in an identified serotonergic neuron of Aplysia californica. Proc. Natl. Acad. Sci. U. S. A. 76: 5967-5971.

Stone, G. C., and D. L. Wilson (1979) Qualitative analysis of proteins rapidly transported in ventral horn motoneurons and bidirectionally from dorsal root ganglia. J. Neurobiol. 10: $1-12$.

Thoenen, H., and Y. -A. Barde (1980) Physiology of nerve growth factor. Physiol. Rev. 60: 1284-1335.

Watson', W. E. (1968) Observations on the nucleolar and total cell body nucleic acid of injured nerve cells. J. Physiol. (Lond.) 196: 655-676.

Watson, W. E. (1970) Some metabolic responses of axotomized neurones to contact between their axons and denervated muscle. J. Physiol. (Lond.) 210: 321-343.

Weiss, K. R., and I. Kupfermann (1976) Homology of the giant serotonergic neurons (metacerebral cells) in Aplysia and pulmonate molluscs. Brain Res. 117: 33-49.

Weiss, K. R., J. L. Cohen, and I. Kupfermann (1978) Modulatory control of buccal musculature by a serotonergic neuron (metacerebral cell) in Aplysia. J. Neurophysiol. 41: 181-203. 